\title{
A REVIEW ON DNA NANOBOTS - A NEW TECHNIQUE FOR CANCER TREATMENT
}

\author{
DEVASENA UMAI R, BRINDHA DEVI P*, THIRUCHELVI R
}

Department of Bio-Engineering, School of Engineering, Vels Institute of Science, Technology and Advanced Studies, Pallavaram, Chennai600 117, Tamil Nadu, India. Email: pbrindhadevi@gmail.com

Received: 29 January 2018, Revised and Accepted: 09 March 2018

ABSTRACT

Cancer is one of the deadliest diseases of this century. Tedious and painful radiation therapy and chemotherapy are administered using many drugs including antitumor antibiotics, which cause a lot of side effects. As an alternate, DNA nanorobots serve as a potential cancer treatment technique which is very much safer than other therapies and acts specifically as well. DNA nanobots are said to set a new milestone in the development of medical studies. The primary objective of this bot is to target and eliminate cancer cells from the human body. These bots are made of a single strand of DNA folded into the desired shape. The bots will have two states - an "off" position, where the clamshells are closed tightly to bypass healthy cells without any damage and an "on" position, where the clamshell opens up to expose cancerous cells to the drug so that the drug can do its job to eliminate the cancer cell. This novel idea will be actively used within the public when it passes its first human trial. In this review, we focus on eliminating cancer cells. Since the bot can be programmed and is capable enough to carry a payload, it can also be used to cure any other diseases as a secondary target. Creation of nanobots has been under progress already and may come within the public after an estimated time of 5 years.

Keywords: Cancer treatment, Nanotechnology, DNA nanobots.

(C) 2018 The Authors. Published by Innovare Academic Sciences Pvt Ltd. This is an open access article under the CC BY license (http://creativecommons. org/licenses/by/4. 0/) DOI: http://dx.doi.org/10.22159/ajpcr.2018.v11i6.25015

\section{INTRODUCTION}

Cancer is a dreadful disease which is unbiased, affecting the rich and poor, adults and children alike. Hippocrates is said to have coined the name "cancer" for this disease. According to a theory by him, there are four fluids in the body, namely, blood, phlegm, yellow bile, and black bile. Increase in black bile causes cancer [1]. A few years back, scientists have detected cancer in the bones of mummies of Egypt [2] and Greece and skeletal remains of a man in Amara west [3] (which is Sudan now). Although cancer was not widespread during ancient times, remedies for cancer have been mentioned in Egyptian literature and art [4]. Scientists believed that the carcinogens from burning wood, from the fireplace, etc., were responsible for cancer in those days. Now, after undergoing many researches, especially on the structure of genes, scientists have come to a conclusion that the changes in human lifestyle, diet, environmental factors, and development of many industries [5], have increased radiation and carcinogens, which obviously lead to cancer. Alcohol consumption, use of tobacco, obesity, age, hormones, and chronic inflammation also lead to this disease [6].

\section{Cancer death rate statistics}

Cancer may be localized or may become systemic if conditions favor it. It is becoming very common in the recent years and has caused millions of deaths. Cancer is next only to cardiovascular diseases in causing death to humans globally [7]. Yet, there is no proper and adequate medication for it. Estimation says irrespective of gender, about $38.5 \%$ of people in the world are affected by cancer at some point in their lifespan [8]

Table 1 shows the worldwide cancer statistics in different years. It is estimated that in 2030, there would be 13.1 million cancer deaths [13]. From all these statistics, it is concluded that lung cancer in men and breast cancer in women are the most commonly diagnosed ones around the world. In India, oral, stomach, and lung cancer in men and cervical, stomach, and breast cancer in women are the most common ones [14]. When compared with the whites, black men have double the chances of death due to cancer. Although white women are affected more by breast cancer, the death rate is predominant in black women. This variation is because of lack of awareness and negligence of timely screening and diagnosis among the black [15]
There are four stages of cancer (Stages I-IV). The TNM system is used to describe the stages of cancer, where T (tumor) refers to the size of the tumor; $\mathrm{N}$ (nodes) denotes that it has spread to the lymph nodes and $\mathrm{M}$ (metastasis) means the cancer has spread to other organs [16,17]. Treatment is given depending on the stage. If diagnosed earlier, most of the cancers can be cured, relieving the patient from the toils of this deadly disease. However, delay in diagnosis, mostly due to symptoms not being apparent, leads to fatal end where the current cancer treatments are of no use. The various cancer treatments that are presently used include chemotherapy, radiation therapy, or a combination of both surgery, immunotherapy, targeted therapy, stem cell therapy, and hormone therapy [18].

Approximately $60 \%$ of cancer patients are treated with radiotherapy or chemotherapy or a combination of both [16]. The primary aim of these therapies is to kill the cancerous cells. However, the surrounding healthy cells also get affected. The key problem with these radio and chemotherapies is not that the drugs are not effective, but that the rest of the body cannot tolerate the high drug concentration [19]. Some infections by carcinogenic viruses can be prevented by vaccines (such as human papillomavirus vaccine [20,21] which prevents cervical cancer, the most common one among Indian women), but there are still many types of cancers affecting trillions of people which cannot be easily cured.

\section{Nanoparticles for cancer treatment}

Nature has always gifted man with many healing herbs. Some such herbs have been found to have anticancer properties which have been proved in recent researches [22], and they are more effective especially in the form of nanoparticles $[23,24]$. Cancer medicines, when formulated as nanoparticles, have more advantages than when in taken as free drugs $[25,26]$. They are specific to the diseased cells; they have no side effects, they increase the solubility of some hydrophobic drugs, they can penetrate inside cells and so on [27]. Cancer immunotherapy focuses on the point that nanomedicines should overcome any hindrance to nanoparticle delivery [28]. However, this needs more research because there are chances that nanoparticles could be mistaken as unwanted foreign bodies by our immune system. There are various methods to overcome the immune responses to the nanoparticles [29]. Meanwhile, in some pathways, nanoparticles cannot enter the cells. They may remain in the extracellular matrix itself [30]. If nanoparticles turn to be toxic, then it becomes a matter of concern [31]. 


\section{Nanorobotics for cancer treatment}

Nanorobotics is the technology of constructing robots in the nanometer scale. $\left(10^{-9} \mathrm{~m}\right)$ [32]. It is an emerging technology in the recent times. Nanorobots and their application in the medical field are currently under development. In collaboration with medicine, nanorobots are programmed to perform specific biological tasks. When they are injected into the blood, they work on cancer cells or any other affected cells. Nanorobots merged with biological research will set a new milestone in the development of medical studies.

The shortcomings of the present methods of treatment are taken into account to hit upon a better therapeutic treatment for this alarming disease. To target only the cancerous cells specifically, without affecting the healthy cells, and to minimize the side effects, Bachelet et al., came up with the idea of DNA nanorobots. Even if diagnosed in the later stages, DNA nanorobots can be effective in curing the disease. The recovery through nanobots is depicted in Fig. 1.

\section{CONSTRUCTION OF NANOBOTS}

Bachelet et al.,[41] designed nanobots made up of DNA which work as a carrier for cancer-treating drugs. These bots, when injected into the body, selectively kill the cancerous cells. These bots are smaller than a red blood cell by 200 times [32] and are only $35 \mathrm{~nm}$ in diameter [33].

To design the structure of the nanorobots, the researchers used an open-source software, called Cadnano [34]. They then built the bots using DNA origami. The technique of making tiny shaped structures out of DNA is called DNA origami [35-38]. DNA can be built into a desired shape by cutting a small portion of it (staple strand) and attaching it to a long strand. The two strands bind due to the interaction between the

Table 1: Global cancer death statistics [7,9-12]

\begin{tabular}{ll}
\hline Year & Cancer deaths (millions) \\
\hline 2000 & 6 \\
2002 & 6.7 \\
2008 & 7.6 \\
2012 & 8.2 \\
2015 & 8.8 \\
\hline
\end{tabular}

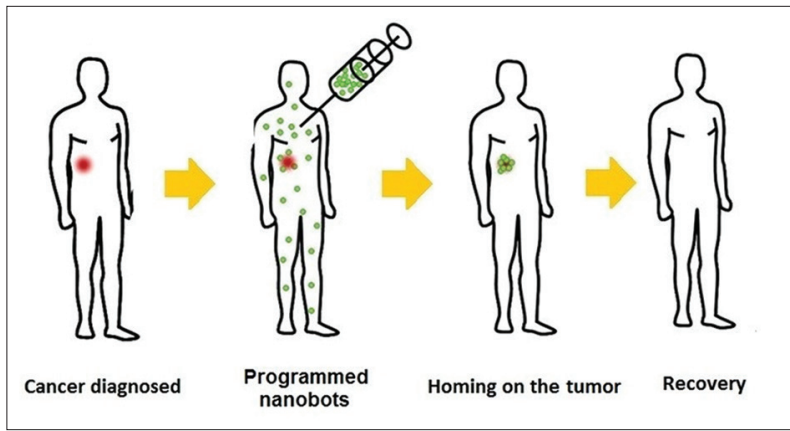

Fig. 1: Recovery through nanobots complementary base pairs and form the desired shape. The design and construction of the bot are depicted in Fig. 2. These bots look like a nanosized open-ended barrel consisting of two halves which can be opened and closed in the form of a clamshell. The two halves are connected by molecular hinges [39] and kept together by molecular locks or latches made of DNA double helixes [32] (Fig. 2). Inside the bots, there are 12 sites for attaching payload molecules [33]. On the outside, there are two positions for attaching aptamers (short nucleotide strands with special sequences for recognizing molecules on the target cell). The drug is loaded inside the nanobot, and it is secured by molecular anchors. The aptamers act as clasps, and once they recognize their target, the device opens up and releases the payload [39].

The nanobots have been programmed to be in 2 states - ON and OFF [40]. Once they recognize a target cell based on its surface proteins, the two halves open up and deliver the drug to that particular cell (on position). In the off position, they are closed tightly and bypass healthy cells.

\section{WORKING METHODOLOGY OF NANOBOTS}

The nanobots are controlled by an aptamer-encoded logic gate [41]. Any type of nanoparticle can be transformed into autonomous biocomputing structures that are capable of executing Boolean logic gates (NAND, NOT, AND, and OR). Since DNA is a natural substrate for computing, it has benefitted a diverse set of logic circuits and robotics [34]. The logicgating functionality is incorporated into the DNA, and the logic gating is achieved through input-induced disassembly of the structures in the DNA [42]. Different forms of DNA-based biocomputing have already been demonstrated. Now, it has been shown that DNA origami can be used to devise nanoscale robots which have the capacity to interact with each other with dynamism when introduced into the body. These interactions produce logical outputs, which are used to open or close the nanobot to release the drug, on spotting the target cell. The $\mathrm{ON}$ and OFF positions of nanobots are depicted in Fig. 3.

\section{PRELIMINARY TRIALS ON NANOBOTS AND ITS MECHANISM}

In 2012, scientists at the Wyss Institute at Harvard University loaded fluorescent-labeled antibodies against human leukocyte antigens into the nanobots to make them bind to the cancer cells in particular. On detecting the target proteins, the bots would release the payload [43]. Later in 2014, Amir et al. injected various nanobots into cockroaches (Blaberus discoidalis) [44] to see how they target the cells and deliver the drug. Each nanobot was labeled with fluorescent markers, and the researchers followed them to analyze how and where they delivered the drug. Bachelet said that the precision of delivery and control of the bots were equivalent to that of a computer system and this was the first time where biological therapy has matched the working of a computer processor [45]. Since these nanobots are cell-specific, unlike the current treatments which are not well-targeted, these bots will be an advanced development in cancer treatment. However, a treatment like this in humans must overcome the immune response of the body. Bachelet is sure that the nanobots can be stabilized to make them survive in the body.

Recently, researchers at the California Institute of Technology have built nanobots which could sort and deliver the drug. The bot consists of three parts - a "leg," a "hand" with an "arm" which carries the drug and delivers

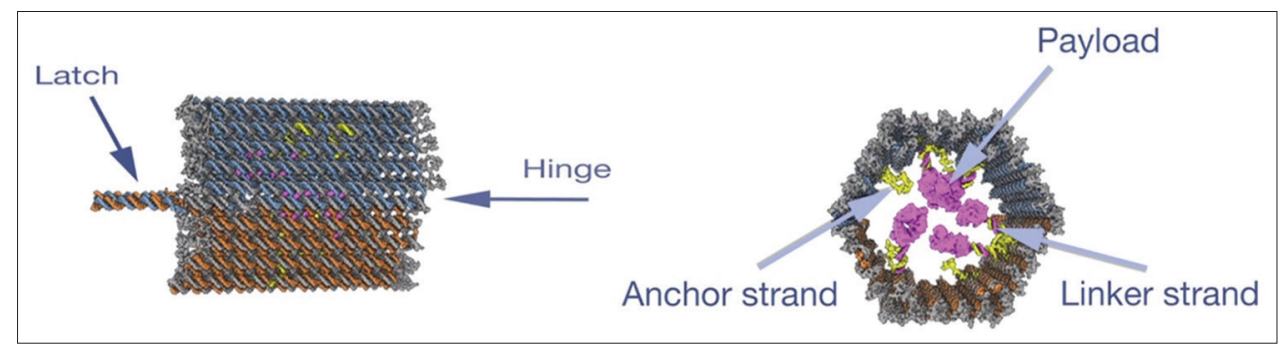

Fig. 2: Construction of the bot 


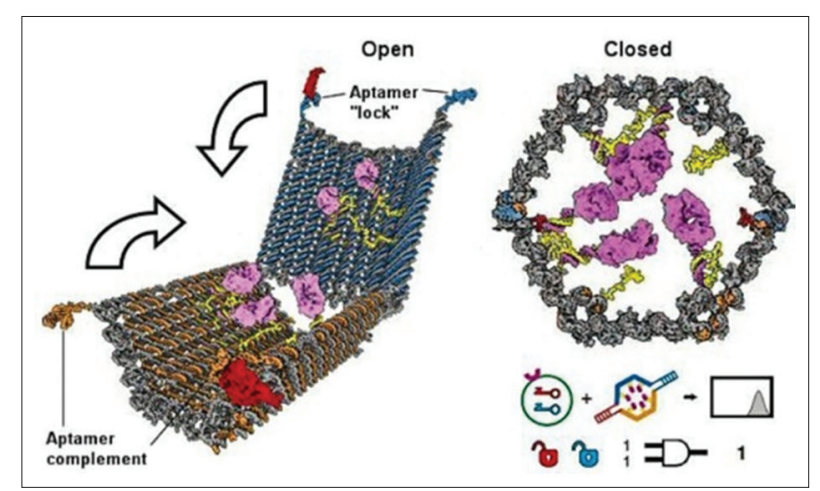

Fig. 3: On and off position [40]

it. There is another component which directs the delivery of the drug. Due to its shape, the bot looks as if it is crawling when it moves [46]. Although these bots were built without any particular purpose, they have a very good application in cancer treatment. Scientists have lately built up nanobots that deliver thrombin, an enzyme which clots the blood that goes to the tumor and thereby destroys the tumor [47-49]. This trial has given hope that nanobots are safe enough and can be used as an effective cancer treatment method.

Preliminary trials on humans are expected to get started within 5 years.

\section{ADVANTAGES OF NANOBOTS}

The speed and durability of the bots are its main advantages. In drug delivery, benefits are abundant through nanobots than that are provided by present methods [50]. There is controlled release of drug which is very specific and accurate with fewer side effects. It minimizes surgeon mistakes. Computer controlled delivery and greater speed of drug action are its supremacy [51].

\section{DISADVANTAGES OF NANOBOTS}

It is expensive to design the nanobots, and a lot of complications are involved in designing them as well [52]. More research work has to be done so that the bots are able to overcome the body's immune response. Nanobots, if misused by terrorists, could even be used as bio-weapons and may become a threat to the society. If nanobacteria that are present in our body can cause serious effects in our body, so can nanobots which are foreign to us [53]. Hence, care has to be taken to overcome this drawback. Our immune system can be challenged if we depend a lot on nanotechnology [54]. If nanobots self-replicate, a harmful version of the bots could be created $[55,56]$.

\section{CONCLUSION}

DNA has been used for storing data and also used to amplify signals when used as circuits, but these uses are primitive when compared to the benefits of the bots [45]. These bots are the best for targeted drug therapy and controlled release of drug as they act specifically and do not affect the surrounding healthy cells. If the trial succeeds then nanotechnology will be a breakthrough in medical studies. If this technology is used as a replacement for the current treatments, side effects can be prevented. Scientists are also into trying acoustic communication among nanobots so that they coordinate and act on the specific site [57]. At present, it is believed that the nanobots can treat cancer completely within a month. In the future, with more improvements, it can be used to cure cancer within a few days or even a few hours, no matter how far the disease has spread. On further research, it can be used even to defend people who have chances of getting cancer, prevent cancers which are hereditary, or where cancer is a sure possibility (like victims of liver cirrhosis).

Scientists are to produce increasingly more complex nanomachines such as red blood cells 2.0 (synthetic particles that are like real red blood cells and can stay longer in the body), microbivores (nanobots capable of destroying pathogens inside the body) [58] and nanobots which suck up ocean pollution [59]. Although they are still in the research and development phase, their potential is innumerable. Nanotechnology can also be used to make smart bandages which can heal wounds faster [60].

\section{Future perspectives}

In the future, medical treatment will expand enormously, reducing the risk and cost because of the development in the field of molecular nanotechnology. DNA nanobots can now identify 12 types of cancer cells [40]. With more trials and development, these bots will create a drastic change in the medical field for the benefit of humans. The bots are expected to reach the common man within 5 years.

\section{ACKNOWLEDGMENT}

The authors thank Vels Institute of Science, Technology, and Advanced Studies management for rendering constant support in writing the review article successfully.

The authors do not have any conflict of interests and both the authors have contributed equally for bringing this review article effectively.

\section{REFERENCES}

1. Sudhakar A. History of cancer, ancient and modern treatment methods. J Cancer Sci Ther 2009;1:1-4.

2. Prates C, Sousa S, Oliveira C, Ikram S. Prostate metastatic bone cancer in an Egyptian Ptolemaic mummy, a proposed radiological diagnosis. Int J Paleopathol 2011;1:98-103.

3. Binder M, Roberts C, Spencer N, Antoine D, Cartwright C. On the antiquity of cancer: Evidence for metastatic carcinoma in a young man from Ancient nubia (c. 1200BC). PLoS One 2014;9:e90924.

4. David AR, Zimmerman MR. Cancer: An old disease, a new disease or something in between? Nat Rev Cancer 2010;10:728-33.

5. Philipkoski K. Egyptian Mummy Had Prostate Cancer; Lots More Ancient Peeps Probably Did Too; 2011. Available from: https://www. gizmodo.com/5854019/egyptian-mummy-had-prostate-cancer-lotsmore-ancient-peeps-probably-did-too.

6. Risk Factors for Cancer. National Cancer Institute; 2015. Available from: https://www.cancer.gov/about-cancer/causes-prevention/risk.

7. Cancer, WHO; 2014. Available from: http://www.who.int/mediacentre/ factsheets/fs297/en/.

8. Cancer Stat Facts: Cancer of Any Type. National Cancer Institute; 2014. Available from: https://www.seer.cancer.gov/statfacts/html/all.html.

9. Parkin DM. Global cancer statistics in the year 2000. Lancet Oncol 2001;2:533-43.

10. Parkin DM, Bray F, Ferlay J, Pisani P. Global cancer statistics, 2002. CA Cancer J Clin 2005;55:74-108.

11. Jemal A, Bray F, Center MM, Ferlay J, Ward E, Forman D, et al. Global cancer statistics. CA Cancer J Clin 2011;61:69-90.

12. Torre LA, Bray F, Siegel RL, Ferlay J, Lortet-Tieulent J, Jemal A, et al. Global cancer statistics, 2012. CA Cancer J Clin 2015;65:87-108.

13. Interesting Facts about Cancer; 2017. Available from: http://www. dllink.co.za/news/item/13-46-interesting-facts-about-cancer.

14. Grace Rattue. What Are the Leading Causes of Cancer Deaths in India? Medical News Today; 2012. Available from: https://www. medicalnewstoday.com/articles/243547.php.

15. Siegel R, Ma J, Zou Z, Jemal A. Cancer statistics, 2014. CA Cancer J Clin 2014;64:9-29.

16. Charles Patrick Davis. Cancer; 2016. Available from: https://www. onhealth.com/content/1/cancer types treatments.

17. Greene FL, Sobin LH. The staging of cancer: A retrospective and prospective appraisal. CA Cancer J Clin 2008;58:180-90.

18. Treatment Types. American Cancer Society; 2017. Available from: https://www.cancer.org/treatment/treatments-and-side-effects/ treatment-types.html.

19. Venkatesan M, Jolad B. Nanorobots in cancer treatment. In: Emerging Trends in Robotics and Communication Technologies (INTERACT), 2010 International Conference on 2010. p. 258-64.

20. Smith L. Human Papillomavirus (HPV): Causes, Symptoms, and Treatments, 13 September; 2017. Available from: https://www. medicalnewstoday.com/articles/246670.php.

21. Kirti PK. Human papilloma virus associated cervical cancer: A review. 
Asian J Pharm Clin Res 2016;9:14-7.

22. Tripathi P, Singh A. Natural resources from plants in the treatment of cancer: An update. Asian J Pharm Clin Res 2017;10:13-22.

23. Preethi R, Padma PR. Anticancer activity of silver nanobioconjugates synthesized from Piper betle leaves extract and its active compound eugenol. Int J Pharm Pharm Sci 2016;8:201-5.

24. Vijay M, Anu Y. Anticancer activity of Camellia sinensis mediated copper nanoparticles against HT-29, MCF-7, and MOLT-4 human cancer cell lines. Asian J Pharm Clin Res 2017;10:82-8.

25. Hemant K, Raisaday A, Sivadasu PR, Uniyal SW, Kumar SH. Cancer nanotechnology: Nanoparticulate drug delivery for the treatment of cancer. Int J Pharm Pharm Sci 2015;7:40-6.

26. Goldberg MS. Immunoengineering: How nanotechnology can enhance cancer immunotherapy. Cell 2015;161:201-4

27. Nguyen KT. Targeted nanoparticles for cancer therapy: Promises and challenge. J Nanomed Nanotechnol 2011;2:1-2.

28. Jiang W, von Roemeling CA, Chen Y, Qie Y, Liu X, Chen J, et al. Designing nanomedicine for immuno-oncology. Nat Biomed Eng 2017;1:29.

29. Chauhan VP, Jain RK. Strategies for advancing cancer nanomedicine. Nat Mater 2013;12:958-62.

30. Nichols JW, Bae YH. Nanotechnology for cancer treatment: Possibilities and limitations. In: Cancer Targeted Drug Delivery. New York: Springer; 2013. p. 37-56.

31. Singh OP, Nehru RM. Nanotechnology and cancer treatment. Asian J Exp Sci 2008;22:6.

32. Raaja DK, Ajay V, Jayadev SG, Kumar M, Karthikeyan NS, Ravichandran C. Mini review on nanobots in human surgery and cancer therapy; 2016. Available from: http://www.ijsrme.rdmodernresearch. com/wp-content/uploads/2016/06/CP-032.pdf.

33. Nikitin MP, Shipunova VO, Deyev SM, Nikitin PI. Biocomputing based on particle disassembly. Nat Nanotechnol 2014;9:716-22.

34. Katsnelson A. DNA Robot Could Kill Cancer Cells; 2012. Available from: https://www.scientificamerican.com/article/dna-robot-kills-cancercells/. [Last accessed on 2012 Feb 16].

35. Rothemund PW. Folding DNA to create nanoscale shapes and patterns. Nature 2006;440:297-302.

36. Jiang Q, Song C, Nangreave J, Liu X, Lin L, Qiu D, et al. DNA origami as a carrier for circumvention of drug resistance. J Am Chem Soc 2012;134:13396-403.

37. Lund K, Manzo AJ, Dabby N, Michelotti N, Johnson-Buck A, Nangreave J, et al. Molecular robots guided by prescriptive landscapes. Nature 2010;465:206-10.

38. Fu J, Yan H. Controlled drug release by a nanorobot. Nat Biotechnol 2012;30:407-8.

39. DNA Nanobots set to Seek and Destroy Cancer Cells in Human Trial - Janet Fang; 2016. Available from: http://www.iflscience.com/ health-and-medicine/dna-nanobots-will-seek-and-destroy-cancercells/. [Last accessed on 2015 Mar 18].

40. Korn D. DNA Nanobots will Target Cancer Cells in the First Human Trial using a Terminally Ill Patient; 2016. Available from: http:// www.theplaidzebra.com/dna-nanobots-will-target-cancer-cells-inthe-first-human-trial-using-a-terminally-ill-patient/. [Last accessed on 2015 Mar 27].

41. Douglas SM, Bachelet I, Church GM. A logic-gated nanorobot for targeted transport of molecular payloads. Science 2012;335:831-4

42. Katsnelson A. DNA Robot could kill cancer Cells. Device Identifies
Target then Releases Deadly Payload. In: Nature News; 2012.p. 16

43. Martz L. DNA nanorobots. SciBX Sci Bus Exchange 2012;5.

44. Amir Y, Ben-Ishay E, Levner D, Ittah S, Abu-Horowitz A, Bachelet I, et al. Universal computing by DNA origami robots in a living animal. Nat Nanotechnol 2014;9:353-7.

45. Spickernell S. DNA Nanobots Deliver Drugs in Living Cockroaches 2014. Available from: https://www.newscientist.com/article/dn25376dna-nanobots-deliver-drugs-in-living-cockroaches/.

46. Padmanabha D. DNA Nanorobot that Picks, Sorts and Drops off Molecular Cargo; 2017. Available from: https://www.biotecnika. org/2017/09/dna-nanorobot-that-picks-sorts-and-drops-off-molecularcargo/. [Last accessed on 2017 Sep 21].

47. Li S, Jiang Q, Liu S, Zhang Y, Tian Y, Song C, et al. A DNA nanorobot functions as a cancer therapeutic in response to a molecular trigger in vivo. Nat Biotechnol 2018;36:258-64.

48. Caspermeyer J. Cancer-Fighting Nanorobots Programmed to Seek and Destroy Available from: https://www.asunow.asu.edu/20180212discoveries-cancer-fighting-nanorobots-seek-and-destroy-tumors. Tumors. [Last accessed on 2018 Feb 12].

49. Cancer-Fighting Nanorobots can Seek, Destroy Tumours. Indian Express; 2017. Available from: http:/www.indianexpress.com/article/ technology/science/cancer-fighting-nanorobots-can-seek-destroytumours-5064129/. [Last accessed on 2018 Feb 14].

50. Bourzac K. Nanotechnology: Carrying drugs. Nature 2012;491:S58-60.

51. Khulbe P. Nanorobots: A review. Int J Pharm Sci Res 2014;5:2164.

52. Daphne C. Disadvantages of Nano Robotics; 2012. Available from: https://www.scribd.com/doc/62640521/Disadvantages-of-NanoRobotics. [Last accessed on 2011 Aug 19].

53. Nano-Risks: A Big Need for a Little Testing, Scientific American; 2010. Available from: https://www.scientificamerican.com/article/big-needfor-a-little-testing/. [Last accessed on 2010 Jan 01]

54. Chang PL. Nanotechnology: Potential Pros and Cons for Humanity; 2014. Available from: https://www.consciouslifenews.com/nanotechnologypotential-pros-cons-humanity/1172870/.

55. Martin S. Self-Replicating Nanobots could Destroy all Life on Earth, Warn Experts; 2017. Available from: https://www.express.co.uk/news/ science/825989/nanotechnology-nanobots-grey-goo-end-of-the-world. [Last accessed on 2017 Jul 07]

56. Kabay ME. Self Replicating Nanobots; 2010. Available from: https:// www.networkworld.com/article/2209510/security/self-replicatingnanobots.html. [Last accessed on 2010 May 24].

57. Loscri V, Natalizio E, Mannara V, Aloi G. A novel communication technique for nanobots based on acoustic signals. In: International Conference on Bio-Inspired Models of Network, Information, and Computing Systems. Cham: Springer; 2012. p. 91-104.

58. Ahmad U. Smart nanobots: The future in nanomedicine and biotherapeutics. J Nanomed Biother Discov 2016;6:140

59. Dujmovic J. Nanobots are Waiting in the Wings to Cure Cancer and Clean up Ocean Pollution; 2017. Available from: https://www. marketwatch.com/story/nanobots-are-waiting-in-the-wings-to-curecancer-and-clean-up-ocean-pollution-2016-06-09. [Last accessed on 2016 Jun 09].

60. Fischman J. Nanomedicine Aims New Treatments at Cancer and Dangerous Wounds; Available from: https://www.scientificamerican. $\mathrm{com} /$ article/nanomedicine-aims-new-treatments-at-cancer-anddangerous-wounds/. [Last accessed on 2015 Apr 01]. 